\title{
Génesis y evolución de la categoría realidad histórica en Ignacio Ellacuría
}

\author{
Marcela Brito \\ Universidad Centroamericana \\ "José Simeón Cañas"
}

Resumen: El presente trabajo tiene como objetivo principal exponer una propuesta evolutiva del pensamiento de Ignacio Ellacuría desde una perspectiva estrictamente metafísica. Para ello, la exposición se realizará en tres momentos fundamentales: juventud (1951-1962), aproximación a la filosofía zubiriana y proyecto de madurez (1962-1974) y la realidad histórica como momento de madurez (1975-1989). En cada una de ellas se realiza una discusión en torno a los problemas fundamentales que marcan el desarrollo del complejo pensamiento de Ellacuría, con la finalidad de arribar a su propuesta del cambio civilizatorio que marcó las reflexiones de los últimos años de su vida y comprender, de esta forma, cómo su pensamiento tiene un carácter novedoso y vigente en nuestra coyuntura nacional y planetaria.

Palabras clave: Ignacio Ellacuria, realidad histórica, metafísica, evolución intelectual.

Abstract: This paper intends to expose an evolutive proposal of Ignacio Ellacuria's thought, from an strictly metaphysical approach. To do that the exposition will be done in three main moments: youth (1951-1962), oncoming to Zubiri's philosophy and maturity project (1962-1974), and historical reality as a moment of maturity (1975-1989). In each one of these moments, there will be a discussion around the fundamental problems that set the development of Ellacuria's complex thought, with the goal of arriving to his proposal of civilization change, that marked the reflexions fo the last years of his life; and to comprehend, in this way, how his thought has a character of newness and it is still valid in our national and global current situation.

Key words: Ignacio Ellacuria, historical reality, metaphysics, intellectual evolution. 
En estas fechas conmemoramos el trigésimo aniversario del asesinato de Ignacio Ellacuría, así como de sus compañeros Ignacio MartínBaró, Amando López, Joaquín López y López, Segundo Montes, Juan Ramón Moreno y también de Elba y su joven hija Celina Ramos. Esta conmemoración, más que de su martirio y muer te, lo es de su vida y legado; y si hemos continuado recordándoles, es porque su obra ha sido potente y se nos ha impuesto. No podemos sino sentir su impelencia y responder acorde, actualizando y poniendo a la altura de nuestro tiempo esta luz de esperanza que nos invita a pensar, para transformar, unas coordenadas históricas transidas por el mal común y el pecado histórico, en unas de vida plena y abundante para nuestros pueblos.

Es en sintonía con este espíritu festivo que el presente ensayo pretende explayar el sentido de la categoría de realidad histórica en el pensamiento de Ignacio Ellacuría, fundador del departamento de Filosofía de esta universidad, rector, maestro, compañero y guía para estas generaciones y las que están por venir. La realidad histórica, pues, debe ser comprendida como una categoría central en el discurrir de su pensamiento no solamente filosófico, sino también teológico, político y universitario, por su carácter articulador y sistemático. De modo que, para comprender su recto sentido, contenido y rigor, hay que comprender su génesis y evolución. Ahora bien, marcar estas pautas genético-evolutivas también requiere de la determinación de la estructura del pensamiento ellacuriano, al igual que su constitutiva situacionalidad y forma de comprender el tipo de enfrentamiento con la realidad que se desgaja de su manera de comprender la vida intelectual.

Lo anterior nos conduce a valorar la vida de Ignacio Ellacuría como la vida de un intelectual en sentido estricto, puesto que, en su vida y obra, praxis y escritos, se ponen de relieve la radicalidad de su inteligencia, fe y honesto compromiso con la realidad, características fundamentales no de quien es mero erudito, sino de quien asume la primacía de la realidad como fuente de su quehacer vital. Difícilmente podríamos separar la dimensión intelectual de la idea de realidad y del carácter mismo de la vida de Ellacuría, corriendo el riesgo de mistificar, neutralizar o deformar su legado. Esta íntima articulación es lo que confiere al pensamiento de Ignacio Ellacuría su peculiar complejidad, puesto que difícilmente podríamos acercarnos a una arista de su obra sin encontrarnos con categorías teológicas, filosóficas y políticas; o lo que es lo mismo, no puede separarse una dimensión respecto de la otra. Ello nos lleva a determinar la índole de la constelación de notas que da forma al sistema total de vida y obra. 


\section{Estructura del pensamiento ellacuriano}

Hemos señalado ya que en Ellacuría hay una articulación sistémica de notas, las cuales, podemos decir, dan paso a una figura de círculos concéntricos 0 en forma de espiral ${ }^{1}$. La razón de esta forma obedece a la índole específica del proceso evolutivo en su pensamiento: hay una progresión gradual en la apropiación de categorías y sistemas, pero esta no es lineal, dado que no hay elementos que se queden "atrás", olvidados, sino más bien estos son incorporados y asumidos superadoramente, elevando el sistema hacia niveles nuevos, pero positivamente apoyados en los previos. En este sentido, la emergencia de nuevos círculos o nuevas espirales -ambas formas, a nuestro juicio, dibujan una figura más precisa del carácter de la evolución específica del pensamiento de Ellacuría- está ya exigida por la subsistencia y permanencia de los anteriores, por lo que cada elemento se reactualiza a la luz de la incorporación de otros, dando un carácter de sustantividad a toda la unidad.

Pero también podemos decir, en este sentido, que el orden dinámico de la estructura evolutiva del pensamiento de Ignacio Ellacuría es de carácter esencial, estrictamente real y no de orden conceptivo. Ello porque la realidad expresa su dinamismo unitario en tres momentos: desgajamiento exigitivo -libera- ción- subtensión dinámica. Cada momento exige, en orden a la suficiencia constitucional de la unidad sustantiva, el desgajamiento de una nueva función de nivel superior que estabilice a la anterior y subtienda dinámicamente la nueva función desgajada. Esta última quedaría liberada y disponible para ocuparse de menesteres transbiológicos, pero sólo en la medida que se encuentra apoyada por la suficiencia de la estabilización y viabilidad de lo biológico que supone la liberación del nuevo nivel $^{2}$. En el caso de la realidad histórica, la cuestión del absoluto y el carácter totalizador de la realidad constituyen el nivel que "envuelve" toda la unidad del sistema, presuponiendo a su vez que los momentos de viabilidad de lo biológico, lo social y lo personal están asegurados: la realidad histórica, como dinamismo liberador de la realidad en todas sus notas y respectivos dinamismos, pierde su sentido e inclusive su realidad de no ser viable la vida biológica de la humanidad en su sentido más básico. La cuestión del fin de la historia, en este sentido material, fue uno de los problemas más urgentes que intentó resolver Ignacio Ellacuría, en sus términos intelectual y práxico.

En el pensamiento ellacuriano, cada momento evolutivo, decíamos, no implica ruptura sino conservación. Pues bien, esta sólo es posible 
porque cada momento requiere desde sí mismo, y en virtud de la unidad principial que sería su idea de filosofía, el desgajamiento de otras vetas problemáticas y autores, que son notas esenciales que talifican la unidad esencial del sistema sustantivo. Lo anterior implicaría que lo propio, el contenido constitutivo de la unidad de la idea de filosofía en Ellacuría, se talificaría por la realidad histórica como núcleo esencial, de modo que su forma sustantiva va cobrando actualidad procesualmente en cada uno de los momentos que la conforman. Podemos presumir que, efectivamente, hay una unidad esencial desde la que se estructuran y talifican todos los demás momentos, conformando una unidad estricta y con la suficiencia constitucional necesaria para ser real en cuanto tal.

Esta unidad sistemática del pensamiento ellacuriano sólo cobra su carácter pleno con la unidad de su persona como realidad radical. Como nos hemos referido ya, hay una idea de filosofía, de realidad, de inteligencia y de fundamento de lo último en Ellacuría cuya operatividad se va haciendo cada vez más patente, en la medida que la totalidad de su pensamiento va madurando acorde a la complejización, conflictividad y exigencias de la realidad histórica vivida por nuestro pensador en el contexto de dictadura militar y guerra civil salvadoreña. Por ello consideramos que hay una fundamental continuidad y radicalización en los intereses que determinan las distintas fases o etapas de su evolución intelectual, más que un abandono o ruptura con los intereses filosóficos, teológicos o políticos de sus momentos de juventud o madurez. Lo anterior, además, nos debe poner en guardia frente a cualquier cerrazón o lectura determinista de su obra, puesto que el periodo que suele tomarse como base para marcar el momento de madurez intelectual arranca a partir de mediados de la década de 1970 , consolidándose durante 1980-1989; sin embargo, estamos hablando aquí de una madurez muy temprana, tan sólo dispuesta en este periodo por acabar la vida de Ignacio Ellacuría en 1989. Difícilmente podemos determinar qué otros derroteros de mayor madurez podrían haber derivado de la obra escrita y publicada en vida, de los artículos y libros que quedaron pendientes, y del desenlace de las circunstancias históricas que Ellacuría ya no alcanzó a presenciar.

Sin embargo, tener en cuenta el carácter tentativo de cualquier intento, como el nuestro, por dilucidar el sentido unitario de esta obra, debe constituirse en un criterio fundamental para atender a los principales elementos que conforman la estructura formal del sistema. El hecho de que muchos textos no pudieran ser terminados no obsta para renunciar a un estudio sistemático de la totalidad de la obra 
ellacuriana, y mucho menos para dar paso a afirmaciones que niegan la constitución de una filosofía y una teología en sentido estricto, relegando el legado de Ellacuría a un ensayo de filosofía o la mera repetición de otros sistemas. Esto equivaldría a negar lo más propio del filosofar en cuanto tal, que es lo que para el caso nos compete: no son los contenidos, sino el modo de enfrentamiento lo que da el sello distintivo al saber filosófico respecto de otros ${ }^{3}$.

Es la ultimidad y radicalidad del afán de verdad y realidad lo que, en definitiva, van a cuajar en la vida de Ellacuría en una filosofía primera propia, original y arraigada en una realidad histórica grávida de justicia, verdad y bien; así como en una teología y una visión universitaria integral cuyos intereses efectivamente responden a una opción preferencial por las mayorías populares o el pueblo crucificado ${ }^{4}$. Dado que hemos hablado ya de la configuración de la unidad estructural de su pensamiento con su persona, de ninguna manera pueden descoyuntarse su fe radical y su rigurosidad intelectual, su talante filosófico y el misterio salvífico que se le reveló en el pueblo salvadoreño y la fe de Monseñor Romero. Es así como cobra pleno sentido la reflexión de Jon Sobrino sobre la articulación de fe y filosofía en la persona de Ignacio Ellacuría:

Pienso que en su teoría de la realidad y en la dirección de su praxis siempre estuvo fiel a ese "más" con que, inexorablemente, se encontró en la historia, y a lo que trató de responder y corresponder: existencialmente no podía negarse a la realidad de una historia siempre grávida del "más", en lo que influia el zubiriano "que la realidad dé más de si", y el magis ignaciano "a la mayor gloria de Dios. ${ }^{5}$

El pueblo salvadoreño, en su escandalosa pobreza y sufrimiento, condujo a Ellacuría a lo largo de su vida en el seguimiento de la figura del Jesús histórico y, en consecuencia, a caminar con las personas más oprimidas en la búsqueda de su liberación ${ }^{6}$. Si bien Ellacuría pudo tener una brillante carrera académica que, en cierta medida le hubiera posibilitado su labor de denuncia, esta no hubiera sido auténtica denuncia, o por lo menos no una que estu- viera positivamente alumbrada por la aplastante realidad del dolor y la miseria en El Salvador y en los países pobres en general. Más aún, Ignacio Ellacuría estuvo consciente de estos riesgos: estar con los pobres implica luchar contra las causas de la pobreza, y con las consecuencias que esto acarrea ${ }^{7}$. Sin la visión que proporciona la buena noticia del advenimiento del Reino para los pobres de este mundo, difícilmente podemos comprender lo que sucedía 
en América Latina en el tiempo que vivió Ellacuría y que, en alguna medida, seguimos viviendo:pensar en el advenimiento del Reino compete repensar lo que se comprende por historia y por historicidad ${ }^{8}$. Sólo en esta medida es posible hablar de una salvación de la historia, operativa en la historia. En la operatividad de la filosofía en la dimensión teologal de la realidad intramundana, Ellacuría hace efectiva la intuición aristotélica y zubiriana: la filosofía, por ser saber que se busca, tiene una característica inespecificidad que le confiere su mayor radicalidad?.

Lo más rico y riguroso de la formación filosófica de Ellacuría en modo alguno quedó perdido entre las urgencias del momento, más bien se operativizó de distintas formas: una teología, una política, una praxis e inclusive una soteriología que buscaron desentrañar las causas últimas del sufrimiento humano y las formas de erradicar el mal a través de la comunicabilidad del bien. Esta centralidad de las víctimas es un topos teórico que le permitió a Ignacio Ellacuría alcanzar la radicalidad y ultimidad propias de la filo- sofía, así como de la teología y del análisis político, en la medida que constituyen lugar que da verdad y, en consecuencia, un enfoque hermenéutico que posibilita un posicionamiento crítico para analizar las coordenadas históricas de las que y para las que la praxis filosófica habrá de ponerse al servicio de la liberación. En este sentido, el carácter liberador de la filosofía y de su objeto, obedecen a la correcta colocación en la realidad desde la negatividad histórica para determinar el horizonte desde el cual habrá de superarse positivamente el signo de los tiempos de la civilización planetaria actual. De ahí que pueda considerarse que la unidad del pensamiento de Ignacio Ellacuría, así como su carácter sistemático y alumbramiento específico de su objeto, vienen dados por la unitariedad de la realidad, específicamente por aquella que viene marcada por el signo de negatividad que marca la pauta de la historia salvadoreña, centroamericana y latinoamericana, caracterizadas por ser de índole más potente, reveladora y con mayores posibilidades de poder dar paso a irrupciones históricas que permitan para el curso de la historia.

\section{Estructura evolutiva y dinámica del pensamiento de Ignacio Ellacuría}

Las reflexiones sostenidas en las páginas anteriores nos conducen, pues, a determinar de qué forma la realidad histórica se convierte en objeto de la filosofía de Ignacio
Ellacuría, desde el lugar hermenéutico y la primacía de la realidad que ya hemos apuntado. Consideramos que pueden establecerse tres fases que ponen al descubierto la 
génesis y evolución de la realidad histórica como eje articulador de la obra ellacuriana. Hemos considerado, tomando como base analítica las propuestas de Héctor Samour, Roberto Valdés, y Jorge Alvarado ${ }^{10}$, la posibilidad de dar paso a una propuesta evolutiva que incorpore elementos valiosos que, a nuestro juicio, apuntan todos los estudiosos de Ellacuría ya mencionados, pero que no unifican la totalidad de su propuesta. Evidentemente, nuestro esfuerzo también es tentativo y no definitivo, pero consideramos que son apuntes que abonan al debate en torno al proyecto intelectual legado por Ignacio Ellacuría.

\subsection{Primera etapa: juventud (1951-1962)}

En un primer momento, ubicamos la etapa de juventud entre los años 1951-1962, la cual abarca los primeros años de formación. Aquí encontramos a un joven Ellacuría, estudiante de filosofía y humanidades en Quito, cuyos maestros fundamentales serán el P.Aurelio Espinoza Pólit, S.J. y el P. Ángel Martínez Baigorri, S.J. Ambos marcarán algunos aspectos capitales del posterior desarrollo intelectual de nuestro autor, en la medida que proporcionan una forma de enfrentamiento con la realidad, la filosofía, la espiritualidad ignaciana y la función universitaria que marcarán el sentido de la búsqueda de la verdad como elemento unificador de la visión teórica, una inteligencia histórica y un lugar hermenéutico desde el cual se puede alumbrar una realidad transida por el pecado y necesitada de liberación. Del Padre Aurelio Espinoza, Ellacuría tomó la profundidad en la aproximación a cualquier problemática como lo más fundamental, por encima de la erudición; pero también la capital importancia de la eficacia en la labor intelectual, universitaria y pública que compete al modelo de trabajo humanizador que él veía encarnado en la autenticidad de la figura del Padre Espinoza:

¿Cómo aunar el trabajo intelectual más serio con una eficacia plena, inmediata y pública, con un atender a tareas múltiples, con un transcender la propia especialización? (...) La palabra que corresponde a este comportamiento es autenticidad; autenticidad, más aún que morah existencial (...). [El P. Aurelio Espinoza] Vio desde siempre que para influir poderosamente hay, antes, que ser ricamente; y que para sobresalir en una línea, hay que haberla elegido conforme a las mejores cualidades de uno mismo y dedicarse a ella con todas las fuerzas ${ }^{11}$. 
El rigor intelectual, en esta etapa, será una constante en todos los momentos posteriores de su evolución, pero no debemos confundir rigor con erudición o inflexibilidad, como ya señala nuestro autor respecto del P. Aurelio Espinoza: Ellacuría tenía claridad sobre la necesidad de tener pleno dominio de los conceptos, sistemas y problemas propios del decurso de la historia de la filosofía para poder discurrir sobre ellos con la seriedad que ameritan las coordenadas en las que se sitúa quien filosofa, corriendo el riesgo de caer en la mediocridad o charlatanería de no cuidar estos aspectos ${ }^{12}$; sin embargo, esta rigurosidad obedece a una fundamental inquietud y actitud de búsqueda que marca la pauta específica del filosofar, y que dan a esta forma de saber no sólo su especificidad, sino también su radicalidad ${ }^{13}$. De ahí que no deba parecernos extraño el interés que tienen la poesía y el cine en el joven Ellacuría ${ }^{14}$ : la inquietud por explorar una sensibilidad que ya está forjándose y que sólo en el contacto con Ángel Martínez encuentra un eco en el cual resuena el esfuerzo intelectual y vivencial por alcanzar la dimensión más esencial de lo real ${ }^{15}$ :

\begin{abstract}
No se trata, pues, de una evasión directa hacia esos mundos de ensueño que llaman poéticos los hombres sedicentes prácticos, sino de una evasión de lo superficial y lo muerto, de lo aparente en las mismas cosas que nos aprietan a cada instante, hacia su ser auténtico y vivo encontrado, a través de una palabra resucitada y ya en podredumbre de muchos días. $Y$ eso si que es una liberación de una esclavitud en que vivimos, esclavitud en que nos mantienen las cosas y la parte más superficial, más carnal, de nosotros mismos ${ }^{16}$.
\end{abstract}

A partir de lo expresado en estas palabras, debemos tener en cuenta que en las valoraciones que Ellacuría hace de la poesía de Martínez no hay dejos subjetivistas ni intimistas, sino una clara búsqueda por lo que de más real, auténtico y transcendente hay en el uso de la palabra como forma de alumbramiento de lo real en cuanto real:

Lo que trato es de buscar una base filosófica de mi posición ante la vida en el sentido de exigir una actitud vital de todo el hombre y además "recreadora", para uno mismo y para los otros, de las comunicaciones vivas de cualquier ser sobre la propia alma (...) A propósito de esto me preguntaba, ¿serán lo mismo poesía y filosofía? Totalmente conforme con Ud. Me respondía que si enfocan como disciplinas totales tienen un largo trecho tantum ratione distinto. Pero en toda su plenitud me parecia 
que la poesía dice una expresividad inefable, una manifestación creadora, mientras que la filosofía es más receptiva, eso si, en una recepción viva que a nosotros nos "re-crea" el objeto conocido. La poesía, una de las clases de poesía -tal vez la más honda, desde luego la más metafísica y ontológica, es decir, real y profunda-, sería el don de la cosa conocida; filosofía por la palabra viva: poesia $a^{17}$.

En este sentido, en el planteamiento de la posibilidad de revelar la totalidad de lo real en la palabra viva que es propia de la poesía y la filosofía, también se vislumbra la visión de estrecha unidad que tendrán para Ellacuría el saber filosófico y la propia interdisciplinariedad de su obra en las siguientes décadas, en la medida que la pregunta por la radical índole de las cosas puede alumbrarse de muchas maneras, como efectivamente quedó plasmado en sus trabajos posteriores en las áreas teológica, política y universitaria, siendo la filosofía el momento de opacidad de la diafanidad que compete a la esencia de lo real en su riqueza. $Y$ es que, en sus años de formación, Ellacuría también tiene clara la historia de la filosofía y el problema que compete a la

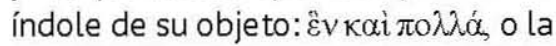
conciliación de lo uno y lo múltiple, lo real y lo aparente, la naturaleza y las cosas, entre otras maneras de formular esta problemática. Entre 1956 y 1958 , publica en ECA dos artículos en torno a esta cuestión ${ }^{18}$ : El despertar de la filosofía no es mero despertar a unos contenidos más o menos eruditos, cuyo cúmulo conformaría lo que suele considerarse como "historia de la filosofía", sino el despertar a una actitud de enfrentamiento con la realidad, donde esta se hace patente en su radical problematicidad.

Asimismo, esta actitud está condicionada por la biografía y la situación de quien filosofa en una época, unos problemas, necesidades y categorías que posibilitan que la reflexión específica y propiamente filosófica pueda aparecer. En este sentido, preguntarse por el despertar de la filosofía, para Ellacuría, implica preguntarse por las condiciones por las que la filosofía puede existir no sólo en Grecia, sino también en cualquier parte:"No carece de actualidad ahora que se empieza a reconocer un surgir auténtico y pujante, acuciado por una interior inquietud, del filosofar en estas tierras tropicales"19. La filosofía, pues, nace de una pregunta que se fundamenta en una actitud intelectual hacia las cosas y, a su vez, dicha actitud se encuentra afincada en una necesidad vital que tiene el ser humano de saber la índole interna y radical de las cosas, más allá de su mera apariencialidad o utilidad. $Y$ es que el análisis que realiza Ellacuría acerca de los presocráticos intenta 
dar cuenta de cómo la filosofía ha surgido, pero también sobre cómo ha podido esbozar, muy esforzadamente, el carácter radical de su propio objeto desde sus momentos más tempranos: la pregunta por lo que son las cosas es el problema de lo último, lo principial, lo esencial y constitutivo de la realidad como totalidad. Ello, además, porque hay en esta radical independencia y dominio del saber filosófico sobre los otros, una función rectora que nuestro autor mantendrá como una constante de su propia reflexión y vida:

\begin{abstract}
(...) es el conocimiento el que vence a la realidad que nos amenaza con sus enigmas, que plantea en la encrucijada de nuestros caminos el problema de la esfinge que sólo desaparece con una recta solución. Dar con la verdad para saber y poder dirigir sus vidas: he ahi la necesaria finalidad del pensador helénico. Es un nuevo y plenario estilo de vida intelectual, puesto que con él se alcanza una razonada y sistemática visión del mundo, que es la que ilumina el comportamiento de la vida y sus posibilidades de obrar ${ }^{20}$.
\end{abstract}

Aquí queda planteado un primer esbozo de lo que Ellacuría intentará resolver en las siguientes décadas: el problema de la unidad transcendental como el último porqué de lo real y de su concreción en la diversidad dinámica, a cuya resolución podrá finalmente arribar en 1981, con su trabajo "El objeto de la filosofía", donde postulará la realidad histórica como objeto de la filosofía, comprendida esta como un saber de orden primero o metafísico por su carácter radical y último ${ }^{21}$. Pero, por lo pronto, lo que nos interesa señalar es que ya desde sus primeros escritos de 1950 y 1960 puede observarse que hay una idea dinámica de la realidad en la forma de aproximarse a la historia de la filosofía y al examinar los intentos de otros filósofos por dar cuenta de este objeto, pero también de la necesidad de dar cuenta de qué forma este objeto unitario está abierto a ese exceso que es la dimensión transcendental de lo real. Hay una sospecha clara acerca del objeto propio de la filosofía y de su carácter, por lo cual Ellacuría se ve en la necesidad de dar con una unidad sintética que exprese la forma que tiene de comprender qué es el filosofar desde una existencia dinámica, abierta a la transcendencia desde la inmanencia, apertura dada por una espiritualidad ignaciana que irá fortaleciéndose en las décadas posteriores. Es aquí donde su esfuerzo por crear una síntesis entre el pensamiento orteguiano y tomista cobra pleno sentido: no es una filosofía cristiana, o una mera necesidad de articular un esbozo filosófico, fruto del impulso juvenil, sino más bien un intento por 
ahondar en lo más último y radical de lo real, que es por definición el objeto de la filosofía ${ }^{22}$.

Es aquí, por otra parte, donde nos encontramos con un interés por conciliar el vitalismo orteguiano con la filosofía tomista como solución a la pregunta por lo unitario, esencial y actual que correspondería a la filosofía como problema, respecto de la índole de su propio objeto. No obstante, es por medio del influjo de maestros como Rahner y Zubiri que Ellacuría encontrará, por la vía de la historicidad, el lugar de apertura desde la inmanencia de lo real para alcanzar dicha radicalidad. Es por ello por lo que debemos considerar que de postular un "abandono" a este proyecto de juventud, caemos en el riesgo de acusar a Ellacuría de inconstante y voluble en sus intereses. En Zubiri encuentra eso que busca y que considera que está implícito en la filosofía de Ortega y Santo Tomás: actualidad de la filosofía, manifiesta en la capacidad de interpretar críticamente la época que se vive a la luz de la tradición en el primero; rigor y sistematismo para dar cuenta de las realidades últimas y de la dimensión transcendental de lo real en el segundo.

En Ortega habla Ellacuría de una existencia desligada, pero profundamente arraigada en la búsqueda de actualizar la filosofía a la altura de la situación en que se vive ${ }^{23}$. No obstante, Ellacuría critica que una de las mayores falencias que tiene la posición orteguiana es su cerrazón a lo que puede aportar una consideración teológica de la realidad a la comprensión de lo social, histórico, humano y del mundo como totalidad $^{24}$. Asimismo, es posible encontrar en Ortega, a juicio de nuestro autor, una actitud propiamente filosófica $y$, en este sentido, cobra pleno sentido el vitalismo característico de su pensamiento; pero, además de la razón arriba apuntada, la carencia de sistematismo fue un impedimento para que los planteamientos orteguianos alcanzaran el carácter sistemático que le compete a una filosofía como la que Ellacuría persigue. Es decir, la radicalidad de las circunstancias que la filosofía pretende comprender y dar cuenta, se queda perdida porque nunca alcanza la ultimidad de lo rea ${ }^{125}$. Por ello, aunque Ellacuría valora la actitud filosófica de Ortega, es muy crítico con los alcances superficiales a los que conducen sus planteamientos asistemáticos, así como el prejuicio típicamente moderno que tiene en su consideración reduccionista de otras formas de conocimiento, como el teológico y el religioso, que impiden la profundización en los contenidos fundamentales que la tradición entrega para continuar comprendiendo el presente ${ }^{26}$.

Respecto de la filosofía de santo Tomás, en cambio, hablamos de una vida religada y en busca del misterio de Dios entregado a los hombres por 
la gracia. Esta cuestión viene referida a algo que Ellacuría observa en el pensamiento tomista: su búsqueda de la sistematización de la totalidad de lo real como presencia deífica en lo mundano, logra "unificar lo múltiple, de profundizar esencialmente en apariencias y accidentes, de jerarquizar definitivamente lo humano como proceso orgánico a partir de un centro religioso que acepta a Dios como el Todo de todo"27. Asimismo, este afán de encontrar a Dios en todas las cosas como se evidencia en el pensamiento tomista es para Ellacuría lo que marca la pauta de la radical originalidad del santo: su capacidad para renovar los contenidos de la tradición y alumbrar, así, lo esencial de la realidad.

Pero el interés por santo Tomás va más allá de lo que pueda actualizarse a la luz de los tiempos -que es, en buen sentido, un paso necesario en la constitución de cualquier filosofía perenne-, sino que también es posible vislumbrar en los textos de Ellacuría la clara contribución que, desde su perspectiva, propicia la doctrina tomista. En Santo Tomás, es posible encontrar una vida intelectual en la cual la profundidad del saber va más allá de las fórmulas repetitivas o de cualquier afán de novedad. Por ello, Ellacuría considera que en los escritos tomistas hay una verdadera búsqueda de la verdad que parte de una actitud humanista que no se contenta con superficialidades ni el mero atenerse a las circunstancias, y es precisamente por esto por lo que su legado intelectual puede considerarse como universal. Esto es, a juicio de nuestro autor, de lo que adolece la filosofía occidental del momento en el que se encuentra situado: "a nosotros nos falta lo que es en sí más importante y permanente, y que en santo Tomás se halla en grado tan eminente: interés metafísico, ansia de luz espiritual, seguridad objetiva, profundidad esencial tras las apariencias existenciales, rigor conceptual y sistemático" ${ }^{\prime 2}$. A ello, podríamos añadir que, en suma, el interés por el aquinate no se centra en los contenidos específicos de su doctrina, sino en el modelo de vida y actitud filosófica que son el paso previo para la constitución de cualquier sistema que intente dar cuenta de la realidad. En este sentido, si en Ortega hay una inquietud por atender a las cuestiones actuales, que es fundamental para una filosofía que se encargue de las urgencias de lo real, en santo Tomás hay un alcance metafísico radical en su forma de escudriñar lo real $y$, en este sentido, un modelo de filosofía perenne que puede tener efectividad si se actualiza a la altura de cada época, no tanto en términos de sus contenidos, sino de su radical afán de verdad por encima de cualquier deseo de originalidad.

Todos estos aspectos quedan patentes en sus escritos de esta primera década, pero se conjugan en una unidad vital que Ellacuría, hacia 
1961, evidencia en la forma peculiar que Zubiri tiene de hacer filosofía y teología, por lo que considerará que

la filosofía zubiriana no sólo asume estos aspectos, sino que también los radicaliza en una unidad sistemática:

Le dije [a Zubiri] suscintamente que veía en él un modelo de juntura entre lo clásico y lo moderno, entre lo esencial y lo existencial. Sonrió y dijo que efectivamente ese había sido el intento de su obra'.

[...] su metafísica nueva, su nueva concepción de la esencia y de la realidad, da una magnífica e inmediata base para una consideración existencial del hombre, cosa que no ocurre con la escolástica. $Y$ esto porque ha radicalizado de tal modo la cuestión, que presenta el fondo de una esencia capaz de abarcar tanto las esencias naturales como las esencias históricas, consecuentemente, al hombre como naturaleza e historia. Por eso se puede decir con verdad que su pensamiento es trans-escolástico y trans-filosofía actual. $Y$ en este sentido, me pone de bruces en el tema central que me interesaba tratar en Zubiri: la superación de dos filosofías que, como resultados, son irreconciliables ${ }^{30}$.

Está de más volver a mencionar que el encuentro entre Ellacuría y Zubiri no obedece a un abandono de este interés, sino todo lo contrario: en Zubiri encuentra una nueva idea de filosofía que viene aparejada con una actitud radical hacia lo real que le permite abarcar desde el estudio cosmológico (Sobre la esencia de 1962, Estructura dinámica de la realidad de 1968, publicado en 1989 ) pasando por el problema de la constitución de lo humano y su peculiar forma de enfrentamiento con la realidad (la trilogía de la Inteligencia sentiente/Inteligencia y realidad, Inteligencia y Logos e Inteligencia y Razón de los años 1981-1983) hasta la cuestión de la religación y el problema de Dios (El hombre y Dios, póstumo de 1984$)^{31}$.

\subsection{Segunda etapa: la gestación del proyecto de madurez y el acercamiento a la filosofía zubiriana (1962-1974)}

Lo apuntado en páginas anteriores nos lleva a la segunda etapa ubicada entre 1962-1974, donde encontramos a un Ellacuría que parte de la filosofía zubiriana y su idea de realidad subtendida sobre el problema de la esencia. Como hemos señalado ya, en sus años 
de formación a Ignacio Ellacuría le interesó profundamente la cuestión de la actitud filosófica y la constitución de una filosofía perenne. Pues bien, estas respuestas las encontró en la filosofía zubiriana, dado que esta, en su radical alcance, parte de una actitud hacia la realidad como forma de orientación no sólo de los contenidos que deben ser propios de la filosofía, sino también como una forma de vida que tiene gran potencial humanizador. Esta cuestión es fundamental, porque es lo que Ellacuría considera como lo propio de la filosofía: "El asombro ha sido, entonces, que Ud. ha dado todo esto de una forma superior, como quien da una solución no al problema mal propuesto, sino a un problema que primero había que replantear" ${ }^{32}$.

Lo que replantea fundamentalmente la filosofía zubiriana es una idea de filosofía, cuyo objeto es la realidad. Es decir, la pregunta que origina la filosofía es la pregunta por las cosas en radicalidad: no se pregunta porque sean esto $o$ aquello, sino qué es lo que son a la luz de la totalidad de lo que hay. Así pues, la pregunta por qué es este todo que alumbra lo que la filosofía ha de problematizarse, lo que origina su propia pregunta y actitud (admiración, angustia o la nada), es la realidad ${ }^{33}$. Cada momento histórico, que la filosofía zubiriana determina como horizontes de problematismo, intenta dar cuenta de cuál es esa raíz fundamental de la cual dimanan las cosas y tienen su carácter de realidad. Pero ello no porque la pregunta por lo que sea la realidad sea una cuestión de pura erudición u ocio vacío, sino porque en la forma de comprender lo que son las cosas, se juega una visión de mundo, una visión de lo humano y una visión de la historia que puede contribuir a la liberación u opresión de la humanidad ${ }^{34}$.

Todas estas cuestiones aparecen en Naturaleza, Historia, Dios (1944), texto con el que Ellacuría se enfrentó por primera vez con el pensamiento de X. Zubiri. En 1961 solicitó su dirección para la realización de su tesis doctoral de filosofía en la Universidad de Comillas, recibiendo una respuesta favorable por parte de Zubiri. Sin embargo, es Sobre la esencia (1962), el que marca de forma definitiva el interés ellacuriano por la nueva metafísica que aparece plasmada en dicha obra: la filosofía de X. Zubiri, como sistema que en un primer momento se desgaja de la impronta fenomenológica instaurada por Husserl, replantea la problemática que intentó solucionar el método fenomenológico, a saber, que alcanzar la determinación de la realidad en su carácter esencial es imposible por el velo o escisión que existe entre la conciencia y el mundo, fruto de la conceptualización de la tradición filosófica anterior. A juicio de Zubiri, si bien es cierto que el ánimo de volver "a las cosas mismas" es una vuelta a la actitud teórica propia de 
la filosofía, el problema no radica en la necesidad de un método que separe a la conciencia del mundo y la esencia de las cosas ("Al separar esos dos momentos -esencialidad y facticidad- y sustantivarlos a beneficio de dos tipos de saber -saber absoluto y saber empírico- Husserl ha descoyuntado la realidad, y la realidad se le ha ido para siempre de las manos" ${ }^{35}$ ), sino, más bien, en que la filosofía no ha reparado en la pregunta de qué es lo que entiende por su objeto fundamental: la pregunta por las cosas, qué es lo que es, no es el problema del ser, sino de la esencia y con ello el problema de la realidad y su estructura. He ahí el or to problemático que Zubiri intentó resolver a lo largo de los casi veinte años que le tomó la redacción de Sobre la esencia, y cuyo desarrollo continuó en las siguientes décadas.

Es desde la lectura de Sobre la esencia que Ellacuría tomará como base metafísica el carácter principial que tiene la realidad, conceptuali- zada por Zubiri como sustantividad desde el análisis interno de la esencia en su carácter estructural, en sus niveles talitativo y transcendental. La tesis doctoral "Principialidad de la esencia en Zubiri", de 1965, nos da una pista fundamental, sobre todo en sus conclusiones, sobre el carácter que tiene la historia como punto de convergencia y apertura entre lo natural y lo transcendental, lo total y lo diverso en dinamismo. Es aquí donde puede localizarse el punto de arranque del proyecto de madurez en Ellacuría: La constitución de una metafísica intramundana cuyo objeto se fundamente en la dimensión histórica de la realidad. La función transcendental de la esencia abierta da paso a la consideración de la persona como realidad personal precisamente por ser de suyo, y por serlo de una forma peculiar, autoperteneciéndose. Es sobre la idea de animal de realidades y de persona, que es posible realizar un abordaje metafísico de la historia como dimensión de la realidad humana:

Persona es el "suyo" de la esencia abierta, un carácter transcendental. El hombre por razón de su talidad intelectiva es "de suyo," transcendentalmente, una esencia abierta. Y en el suyo de la esencia abierta es en lo que transcendentalmente consiste el ser persona. En esta esencia abierta que es la persona queda anclada la posibilidad de ver cómo esencialmente el hombre puede ser una realidad eventual y aun histórica. Para explicarla no hay que partir del hombre como sustancia, pero tampoco del hombre como existencia. Es un error creer que hay anterioridad o prioridad fundamental de la existencia sobre la esencia ni siquiera en la realidad humana. Trátase no de una prioridad de la existencia sino de la estructura esencial que acabamos 
de insinuar, el mero existir no es sino un reducto metafísico del de suyo. Sin una prioridad del de suyo, el hombre no sería realidad ${ }^{36}$.

Posteriormente, entre 1965 y 1967, Ellacuría realiza sus estudios de doctorado en teología en la Universidad de Comillas, en Madrid, pero no llegó a hacer la tesis. Sin embargo, hay que resaltar que el problema sobre el cual versaría su investigación era la idea de religación en Zubiri ${ }^{37}$. Este objeto de estudio es fundamental, porque, aunque Ellacuría no realizó una investigación a la manera del problema de la esencia y sólo dedicó un artículo a este problema, titulado "La religación, actitud fundamental del hombre" $(1966)^{38}$, es una cuestión que aparecerá más adelante en sus escritos teológicos y en Filosofía de la realidad histórica. Es aquí donde Ellacuría encontrará el foco de la apertura de la realidad intramundana personal en su ligazón al poder de lo real. Pero abordaremos eso más adelante.

En 1968 Ellacuría asiste al curso Estructura dinámica de la realidad, impartido por Zubiri, donde quedará referida por primera vez la categoría de realidad histórica. Es así como la consideración de la historicidad como estructura metafísica y real será el aporte que Llevará a Ellacuría a considerar hacia la década de los 70 a la realidad histórica como objeto filosófico apoyado en las demás estructuras y dinamismos de lo real. Por otra parte, si bien es cier to que entre 1968 y 1974 Ellacuría se dedica a la difusión del pensamiento zubiriano en múltiples artículos, cursos y conferencias, también es cierto que sus reflexiones conducirán, entre 1974 y 1976, a plantear un sistema metafísico propio sobre la base de la filosofía zubiriana y sus presupuestos sobre la dinamicidad, sistematicidad, unitariedad y diversidad de lo real ${ }^{39}$. Lo que nos interesa señalar en este periodo, donde ya situamos el tránsito hacia la madurez (entre 1976-1989), es que se empieza a hacer evidente la apropiación del ellacuriana sistema zubiriano: hay un diálogo, desde las bases metafísicas, epistemológicas y antropológicas del primero, con otros autores y problemáticas, pero tomando a la realidad histórica como horizonte de visión teórica de la realidad. Fundamentalmente, serán Marx y Hegel los principales interlocutores en la discusión en torno al problema del estatuto metafísico de la historia, pero también de las dimensiones social y personal como momentos que de suyo le competen de cara a la totalización de la historia ${ }^{40}$.

Asimismo, el problema del carácter histórico de la filosofía y la dimensión metafísica de la historia es abordado en su trabajo "Filosofía y política”, de $1972^{41}$, donde Ellacuría 
explaya la imbricación entre filosofía, política e inteligencia. Es aquí donde podemos observar la radical importancia de la inteligencia como constitutiva situacionalidad histórica como principio de politización de la vida humana en sus dimensiones personal y social. Por otra parte, es este carácter histórico del que pende la recta comprensión de la praxis filosófica: la politización propia de la filosofía no responde a un compromiso partidista, ni con los intereses predominantes de un momento histórico dado, sino a su propio objeto y forma de enfrentamiento radical con lo real: "Efectivamente, allí donde entra la actualización de posibilidades y la socialización -en sentido metafísico- de esa actualización, no puede menos de ocurrir la politización también metafísica de la realidad $y$, consiguientemente, de la reflexión última, total y concreta sobre esa realidad" 42 . Es el carácter dinámico de la realidad y de sus estructuras a nivel histórico el que determina la forma cómo la inteligencia ha de penetrar en sus momentos procesuales para dar cuenta de las condicionantes mismas del propio ejercicio filosófico. Sólo así, la filosofía misma y quien filosofa puede estar plenamente consciente frente a intereses, ideologías y prácticas que puedan distorsionar su dimensión crítica y práctica. Es la politización, a juicio de Ellacuría, la que pone al descubierto la radical historicidad de la inteligencia y la forma de saber, sentido y forma de vida que deberá configurar la filosofía para ser plenamente lo que $\mathrm{es}^{43}$.

Estas formulaciones sobre lo específico de la filosofía y su objeto, la realidad histórica, las que aparecen ya sistemáticamente formuladas en Filos ofía de la realidad histórica. En esta obra, Ellacuría examina las componentes material, espacial, temporal, filética, social, personal e históricas de la realidad, hasta llegar al problema del mal, la praxis, las fuerzas de la historia y la absolutización y totalización de esta ${ }^{44}$. No obstante, este texto nunca fue terminado: Ellacuría sólo llegó a escribir cuatro capítulos ${ }^{45}$, siendo el último donde se dedicó a abordar qué es formalmente la historia, en sus dimensiones de capacitación y posibilitación como dinamismos constituyentes de su proceso de apertura por la vía de la praxis social e individualmente entendida, como apropiación optativa de posibilidades y el problema de la realidad personal frente al absoluto. Nuestro autor planificó incluir otros capítulos dedicados a plantear las cuestiones referidas al sentido de la historia, el sujeto de la historia, el absoluto, entre otros, pero estos no llegaron a ser escritos. Sin embargo, en 1974 desarrolla el curso "El sentido del hacer histórico" y en 1978 y 1987, el curso denominado "El sujeto de la historia", que nos dan pistas del derrotero que tomaría su manuscrito de $1974{ }^{46}$. 


\subsection{Tercera etapa: etapa de madurez. La radicalidad de la filosofía de la realidad histórica (1974-1989)}

Estas discontinuidades en la redacción de la obra se deben sobre todo al ingente trabajo como docente, investigador, rector y negociador en el proceso de pacificación de la sociedad salvadoreña en este periodo. Ellacuría continúa publicando artículos y dando cursos de metafísica, ética, la filosofía zubiriana, teoría crítica, el pensamiento hegeliano, entre otros, además de sus trabajos dedicados a la teología y al análisis coyuntural de la situación política en El Salvador ${ }^{47}$; pero a la luz de la realidad histórica como categoría metafísica totalizante e iluminadora de las dimensiones de la realidad que abordan estos trabajos. Asimismo, hay que señalar que Ellacuría plantea un esbozo de su idea de filosofía en su trabajo de 1976, “Filosofía, ¿para qué?", donde aborda de forma general los tres ejes que, a su juicio, componen la unidad de la praxis filosófica: filosofía como forma de vida, como forma de saber y como principio de desideologización.

En el primer punto, Ellacuría retoma la idea de la politicidad como elemento propio de la forma de vida propiamente filosófica, que él considera plasmada en la figura de Sócrates: el escudriñar la índole de las cosas no obedece a un mero afán de fruición intelectual, sino sobre todo a lo que de verdadero pueda aportar este saber a la vida comunitaria. En este sentido, los momentos ético y político son intrínsecos a la filosofía por el carácter radical de su objeto y por su respectividad a la vida humana ${ }^{48}$. Ahora, esto no implica, según Ellacuría, que la filosofía tenga que plegarse a otras formas de saber, como lo serían la política, la ciencia o la antropología, sino que el filósofo ha de enfrentarse con la realidad, el saber y lo humano de una manera peculiar:

Dentro de esta búsqueda de lo que es el saber, el filósofo sigue un camino propio. Se pregunta como el cientifico por el porqué de las cosas, pero entiende ese porqué de un modo peculiar; está persuadido de que no sabe nada si no se sabe su porqué, pero está también convencido de que no se sabe perfectamente una cosa hasta que conoce su último y total porqué. Y este último total porqué no es para él la ley que enuncia la conexión de un antecedente con su consecuente, sino la estructura misma de la realidad, entendida en su unidad total y última $a^{49}$. 
En este sentido, es la especificidad misma de la filosofía, en su hondura metafísica, la que conduce al hombre a lo más profundo de la realidad, pero manteniéndolo retenida en ella misma, de modo que esta forma de iluminación de las cosas es la que posibilita que, desde la filosofía, también puedan iluminarse la multidimensionalidad de lo real. Es por ello por lo que, entre filosofía, política, ciencia, antropología, entre otras formas de saber, no hay punto de contradicción sino distintas formas de preguntarse y penetrar en estas dimensiones de lo real en sus aristas de nuda realidad y realidad histórica. $Y$ es que no puede obviarse, desde el análisis ellacuriano, que la cuestión histórica sea fundamental para la recta comprensión de lo que es lo real, dado que, si lo real es intrínseca apertura dinámica posibilitante, es en la vida humana donde radica su máximo grado de apertura: "la historia como el lugar de planificación y de revelación de la realidad: el hombre socialmente considerado y haciendo historia es el lugar de la manifestación de la realidad" 50 . Es la entrada de lo humano en el ámbito de lo real lo que determina a la historia - por lo menos materialmente-y le confiere su carácter de sentido, por lo que la filosofía necesariamente ha de preguntarse, en su pregunta por el fundamento último de lo real, cuál es el sentido de la vida humana, la historia y lo real.
Es en este último aspecto donde entra, desde el carácter de la politicidad y el sentido último de lo real, el carácter principial que tiene la ideologización como momento de desenmascaramiento de los intereses que condicionan toda producción teórica humana y sus respectivas concreciones históricas, en la medida que, si el objeto del saber filosófico es lo último de lo real a través de la retención de la inteligencia en esta ultimidad, en el plano de lo histórico esto implica iluminación o desvelación de los condicionamientos bajo los cuales emergen visiones totalizadoras de la realidad que se revisten de un halo de verdad y racionalidad. Lo anterior desemboca en la pregunta por el tipo de ejercicio filosófico que se requiere para que la filosofía realmente se encargue de la realidad, desde la tradición, pero sin ser mera repetidora de esta, sino positivamente arraigada en la altura histórica en la que se encuentra quien filosofa para ser principio de duda, negación y, por tanto, desideologización ${ }^{51}$.

Lo ya apuntado conduce a que, en 1981 y 1985 , Ellacuría sistematice tanto su idea de filosofía, como su respectivo objeto y función. En 1981 publica "El objeto de la filosofía", fundamentando la realidad histórica como objeto metafísico. Así, pues, la realidad histórica envuelve superadoramente los objetos filosóficos de Hegel, Marx y Zubiri, elevándose cualitativamente como forma más alta de realidad: 
En efecto, la realidad histórica, ante todo, engloba todo otro tipo de realidad: no hay realidad histórica sin realidad puramente material, sin realidad biológica, sin realidad personal y sin realidad social; en segundo lugar, toda forma de realidad donde da más de síy donde recibe su para qué fáctico -no necesariamente finalistico- es en la realidad histórica; en tercer lugar. esa forma de realidad que es la realidad histórica es donde la realidad es "más" $y$ donde es "más suya", donde también es "más abierta". (...) Así, por "realidad histórica" se entiende la totalidad de la realidad tal como se da unitariamente en su form a cualitativa más alta y esa forma especifica de realidad es la historia, donde se nos da no sólo la forma más alta de realidad. sino el campo abierto de las máximas posibilidades de lo real ${ }^{52}$.

Nos encontramos pues ante una metafísica propia, original y nacida desde las coordenadas de la realidad del tercer mundo, con miras a analizar la unidad total del proceso histórico para dilucidar las posibilidades reales de liberación desde la negatividad histórica como exigencias propias de la primacía de la realidad ante la inteligencia y como una clara muestra de la superación del reduccionismo idealista de la realidad:

Es bastante claro desde el propio planteamiento que un objeto tal como el de la realidad histórica, entendido como aqui se ha dicho, deja abiertas posibilidades reales para teorias y prácticas distintas, ya que la unidad de la realidad histórica no es monolítica. Se ha dicho que intramundanamente no ha habido 'una' historia, propiamente tal hasta tiempos recientes. Hoy es cada vez más 'una', aunque esta unidad sea estrictamente dialéctica y enormemente dolorosa para la mayor parte de la humanidad. Aunque se habla de distintos mundos (un Primer Mundo, un Tercer Mundo, etc.), el mundo histórico es uno, aunque contradictorio. Quizá sólo lograda la unidad del mundo empírico y de la historia constatable, haya llegado la hora de hacer de esa única historia el objeto de las diferentes filosofías ${ }^{53}$.

Es por ello por lo que no debe extrañarnos que de la forma específica en que Ellacuría comprendió la filosofía, su objeto y propósito, se desprendan otras líneas fructíferas de análisis, como una filosofía de la liberación, una teología de la liberación, una filosofía de la historia o una teoría crítica, entre otras. Su artículo de 1985, “Función liberadora de la 
filosofía", parte de los presupuestos que hemos expuesto en páginas anteriores: toda filosofía de primer orden, es decir, que se ocupe de lo último y radical de la realidad como aquella que persiguió en sus años de juventud-, debe ser de suyo liberadora, crítica y creativa; y, en este sentido, debe enfrentarse con el lugar teórico desde el cual se filosofa para analizarlo y transformarlo en el orden liberador que exige cada momento histórico en el que se encuentra quien filosofa.

Este trabajo mantiene conexión con "Filosofía y política", en la medida que sistematiza una reflexión, desde su idea de filosofía cuyo objeto es la realidad histórica, sobre la función que le compete a la filosofía como forma de saber situado y, por ello, arraigado a la realidad por el carácter radicalmente abierto que tiene el hombre como animal de realidades. Lo que nos interesa señalar de este trabajo es el carácter parcial que tiene la filosofía como principio de revelación de la realidad: esta parcialidad queda marcada por el lugar de mayor negatividad histórica, las víctimas de la historia, que ponen al descubierto las contradicciones y efectos de una determinada forma de comprender el mundo, sustentada en una visión reduccionista de lo real, lo histórico, lo humano y lo personal. Dadas estas circunstancias históricas, Ellacuría sostiene que la función que le compete a la filosofía, al estar al servicio de la verdad y de la plenitud de esa verdad, es la liberación:

\begin{abstract}
El aspecto principal de la finalidad estaria indudablemente en la liberación de esas mayorías, pues ese sería el objetivo principaly hasta cierto punto el horizonte fundamental del quehacer filosófico; pero estrechamente relacionado con él estaría el de la constitución de una nueva filosofía -tantas y tan seguidas ha habido-que realmente pudiera llam arse latinoamericana si es que fuere pensada desde la realidad y para la realidad latinoamericana y al servicio de aquellas mayorias populares que definen esa realidad por su número y también por su capacidad de cualificarla $a^{54}$.
\end{abstract}

La liberación no debe entenderse, por otro lado, como un fenómeno meramente político o económico, sino totalizador, es decir, que debe abarcar transcendentalmente todo lo que compete a la realidad histórica. De ahí que esta función liberadora tenga dos momentos: a) una función crítica; b) una función creadora o creativa, donde la primera se orienta como crítica hacia la ideología dominante como momento estructural de un sistema social, así como todos los demás órdenes de la vida en dicho sistema, en la medida que la ideología no solamente configura formas 
de pensar, sino también estructuras objetivas y relaciones sociales. Ahora, esto nos lleva a aclarar lo siguiente: para Ellacuría, la ideología en y por sí misma no es un fenómeno bueno o malo, sino que debe entenderse en toda su complejidad, porque busca dar cuenta de la realidad, así como proporcionar una justificación y una explicación teórica, racional, que aspire a tener carácter de verdad y a ser buena: "es una explicación coherente, totalizadora y valorizadora, sea por medio de conceptos, de símbolos, de imágenes, de referencias, etc., que va más allá de la pura constatación fragmentada tanto de campos limitados como, sobre todo, de campos más generales y aun totales" 55 . En este sentido, la ideología tiene un cierto carácter de necesidad histórica, porque persigue la conservación y estabilidad de un sistema social y cultural.

No obstante, en el polo opuesto radica la ideologización, cuyas características fundamentales, siguiendo a Ellacuría, consisten en la pretensión de que a nivel social se considere como verdadero y justo lo que realmente no lo es. Es decir, la ideologización pretende apariencia de verdad y, para justificar la situación histórica que produce, apela a grandes principios abstractos que enmascaran intereses inconfesables y que tienden a naturalizar una situación donde las privaciones de muchos son para goce de derechos de unos pocos ${ }^{56}$. Frente a este fenómeno de carácter histórico, la filosofía tiene en su propia razón formal un componente de crítica frente a las estructuras fácticas que no puede quedarse en la mera discursividad, so pena de complicidad de facto con las estructuras opresoras.

Es por ello por lo que el carácter creativo y utópico de la filosofía necesariamente debe ser principio de realización de la crítica para liberar real e integralmente a quienes son víctimas de la lógica de dominación que subyace a la ideologización. Si la ideología y la ideologización son aspectos de la actividad real e histórica del ser humano, es porque estas se encuentran imbricadas en la constitución de las formas de comprender la realidad y de su respectivo momento práxico que corresponden a cada momento histórico o, más bien, lo van configurando y dinamizando de forma abierta. De ahí que todo momento práxico vaya acompañado de un momento ideológico que lo dinamiza. Todo esto nos lleva a considerar que para que la filosofía sea verdaderamente liberadora, necesariamente debe aparejarse con una praxis que también libere respecto de ese momento histórico y de ese sujeto de la liberación que es también histórico:

La praxis liberadora es principio no sólo de corrección ética, sino de creatividad, siempre que se participe en ella con calidad 
$e$ intensidad teóricas y con distancia crítica. Dos palabras sobre el momento fecundador de la presencia y sobre el momento corrector de la distancia. La praxis histórica es ella misma principio de realidad y principio de verdad en grado supremo. Es principio de realidad en cuanto en ella, integralmente entendida, se da un summum de realidad; es principio de verdad, tanto por lo que tiene de principio de realidad como porque la historización de las formulaciones teóricas es lo que, en definitiva, muestra su grado de verdad y de realidad ${ }^{57}$. (pp. 58-59)

Pero esta unidad entre teoría y praxis también debe ponernos en alerta frente a la idea de que existen diversas praxis aisladas. Lo que hay son manifestaciones concretas de una sola praxis: la del cuerpo social. Lo que esas praxis concretas hagan o dejen de hacer, también será reflejo del momento teórico y la estructura social en la que se encuentran afincados los grupos que las llevan a cabo, en la medida que son resultado de una apropiación decisional de posibilidades, que son de liberación o de opresión.

\section{A manera de cierre: la radicalidad de la realidad histórica en la civilización de la pobreza (1989)}

En nuestra situación, que es en buena medida la misma situación histórica de negatividad desde la que Ellacuría partió para analizar la realidad, el signo de negatividad que imprime la civilización del capital supone una exigencia para la universidad, la academia, las organizaciones populares y la sociedad civil desde esta nueva idea de filosofía y su objeto específico, la realidad histórica y su función liberadora, crítica y creativa. Por ello, en 1989, Ellacuría escribió uno de sus trabajos más insignes: "Utopía y profetismo desde América Latina. Un ensayo concreto de soteriología histórica" ${ }^{88}$, donde es evidente cómo la realidad histórica opera como horizonte teórico desde el cual se analiza la superación de esta civilización del capital como forma estructurante y totalizadora de la realidad planetaria, para dar paso a una nueva civilización, la civilización de la pobreza. El problema de la negatividad histórica plantea a la filosofía la necesidad de echar mano de una pastoral que transmita la denuncia de los males de nuestro tiempo pero que, a su vez, proponga nuevos valores, formas de vida y praxis que erradiquen el mal histórico que implantan las ideologizaciones enmascaradoras de la realidad, al encontrar en las mayorías populares este lugar de revelación y negación de dicha negatividad. 
La efectividad de la filosofía de Ignacio Ellacuría, así como de su teología y su análisis político se verifica en el martirio como manifestación del poder idolátrico del dinero, el individualismo, la doctrina de la seguridad nacional y el egoísmo que busca silenciar a las voces que denuncian y anuncian proféticamente las consecuencias de una forma de vida que no es éticamente buena ni universalizable, pues la revelación de su falsedad queda patente en la existencia masiva de miseria, pobreza, opresión, represión, terror y muerte de la mayor parte de la humanidad; las víctimas de la historia. La vida humana bajo el signo del capital es una mala solución para el planeta, por los altos niveles de recursos que exige el estilo de vida que los países industrializados y las potencias mundiales exigen para subsistir ${ }^{59}$. De modo que la civilización de la pobreza, si bien es cierto Ellacuría nunca planteó ninguna fórmula para su dinamización y realización, puesto que son las grandes mayorías crucificadas de la humanidad las que deben plantear las exigencias epistemológicas, prácticas y éticas de su concreción, parte de lo que Ellacuría denomina como "conversión" o la transformación de la humanidad como criterio iluminador teórico y práxico que permita dar voz a este lugar de mayor revelación de la verdad ${ }^{60}$. Es decir, si lo que configura nuestra altura histórica es el mal, debe ser el lugar de revelación de este mal el momento de negación de este, lo cual exige dicho momento de conversión y, por tanto, de revelación de la verdad, que haya un dejarse cargar por el poder de lo real. Es aquí donde el problema de la religación cobra una fundamental relevancia para comprender la iluminación que arroja la realidad histórica como horizonte metafísico y totalizador, porque en la medida que la realidad intramundana de la persona se pueda abrir al poder de lo real para enfrentarse con este, cargar con este y encargarse de este, es posible vehicular el sistema de posibilidades actual hacia uno que personalice, humanice, capacite y posibilite la liberación total e integral de la familia humana del poder del pecado histórico ${ }^{61}$.

Esta liberación integral de la humanidad es lo que Ellacuría denominó en clave teológica como salvación histórica, porque supone no solamente un momento de emancipación sociopolítico y económico para los pueblos empobrecidos y reprimidos, sino también un cambio de orden cultural, valorativo y personal: cambiar el trabajo que oprime y explota, el consumismo desenfrenado y la vacuidad del sentido de la vida, la entretención que no trae felicidad, por el trabajo humanizante y la valoración del ser por encima del tener ${ }^{62}$. Cómo se darán estas transformaciones, dependerá fundamentalmente de cómo escrutemos el signo de los tiempos y nos dejemos poseer por la 
verdad que revela el poderío de los descartados de la historia, para que estos sean brújula y criterio de verificación de la teoría y praxis constitutivas de la filosofía como forma de saber que busca alcanzar lo más radical y último de la realidad. En la filosofía de Ellacuría podemos asistir a un irrefutable hecho: lo último y radical se manifiesta entre los oprimidos cuyos clamores suben hasta el cielo, parafraseando a San Romero de América, por lo cual la filosofía debe inexcusablemente responder a esa realidad y asumir su riqueza, abandonando el afán de universalismo homogeneizador y de aséptica racionalidad que todavía lastran esta actividad de escrutinio de la realidad, por uno de esperanza crítica, efectiva $\mathrm{y}$ realista.

Esta inmersión radical en lo más hondo y mistérico de la realidad a la cual está abocada la filosofía en cuanto tal, es la misma a la que nos exhorta Ignacio Ellacuría a través de la realidad histórica como fundamento teórico y horizonte iluminador de nuestra realidad globalizada actual. En este sentido, la filosofía de la realidad histórica constituye un sistema metafísico fuerte nacido de las coordenadas históricas marcadas por la maldad histórica, que persigue su liberación radical al arraigarnos en la realidad concreta y ponernos al servicio de la liberación integral de nuestros pueblos. De modo que la filosofía, desde nuestro lugar hermenéutico, debe partir de la parcialidad preferencial por los oprimidos para alumbrar nuevas formas de totalización y absolutización de nuestro mundo actual, que peligra por crisis climáticas, guerras, agotamiento de los recursos naturales y un alarmante incremento de la pobreza, exclusión, racismo, machismo y otros males que hacen del fin de la historia una realidad cada día más patente ${ }^{63}$. Tras estas palabras de advertencia, de aviso de incendio, si se quiere, debemos recordar la exigencia, en su último discurso del 6 de noviembre de 1989, que Ellacuría nos plantea en la altura histórica actual: la de comprender nuestra configuración actual para cambiar el rumbo por el cual nos dirigimos al despeñadero de la historia, animados por la esperanza y la necesidad de comunicar el bien para revertir la comunicabilidad y poderío del mal que da muerte sistemática e impunemente: "Lo que queda por hacer es mucho. Sólo utópica y esperanzadamente uno puede creer y tener ánimos para intentar con todos los pobres y oprimidos del mundo revertir la historia, subvertirla y lanzarla en otra dirección ${ }^{64}$.

\section{Referencias bibliográficas}

- Burke, K. Lasalle-Klein, R. (ed.) Love that produces hope: the thought of Ignacio Ellacuría. Minnesota: Liturgical Press, 2006. 
- Ellacuría, Ignacio. “Conclusión: Carácter principial de la esencia”. Tesis doctoral La principialidad de la esencia en Xavier Zubiri. http://www.uca. edu.sv/centro-documentacion-virtual/wp-content/uploads/2015/03/ C07-1.c3.pdf

- ---. Cursos Universitarios. San Salvador: UCA Editores, 2009.

- ---. Escritos filosóficos vol. I. San Salvador: UCA Editores, 1996.

- - - - Escritos filosóficos vol. II. San Salvador: UCA Editores, 2007.

- ---. Escritos filosóficos vol. III. San Salvador: UCA Editores, 2001.

- -- - Escritos teológicos vol. I. San Salvador: UCA Editores, 2000.

- ---. Escritos teológicos vol. II. San Salvador: UCA Editores, 2000.

- -- Filosofía de la realidad histórica. San Salvador: UCA Editores, 1990.

- ---. Veinte años de historia en El Salvador (1969-1989). Escritos políticos vol. I. San Salvador: UCA Editores, 1991.

- Samour, Héctor. Voluntad de liberación: el pensamiento filosófico de Ignacio Ellacuría. San Salvador: UCA Editores, 2002.

- Seminario Zubiri-Ellacuría. Voluntad de vida: ensayos filosóficos. Managua: UCA Managua, Managua, 1993.

- Sobrino, J., Alvarado, R. Ignacio Ellacuría: «aquella libertad esclarecida». San Salvador: UCA Editores, 1999.

- Zubiri, Xavier. Sobre el problema de la filosofía y otros escritos (1932-1944). Madrid: Alianza Editorial-Fundación Xavier Zubiri, 2002.

- ---. Sobre la esencia. Madrid: Alianza Editorial-Sociedad de Estudios y Publicaciones, 1985.

\section{Notas}

1 Samour, Héctor. Voluntad de liberación: el pensamiento filosófico de Ignacio Ellacuria (San Salvador: UCA Editores, 2002), 30. Samour es el primer estudioso del pensamiento de Ellacuria que ha sistematizado su pensamiento y diseñado la base de su estructura evolutiva. Por tal motivo, el aporte de Samour suele ser la base que muchos investigadores utilizan para poder estudiar e interpretar la obra de Ignacio Ellacuría.

2 Zubiri,Xavier.Sobre la esencia (Madrid:Alianza Editorial-Sociedad de Estudios y Publicaciones, 1985), 363-365.

3 Ellacuría, Ignacio. "La idea de filosofía en Xavier Zubiri", en Escritos filosóficos vol. /I (San Salvador: UCA Editores, 2007), 369-374.

4 Véanse "La Iglesia de los pobres, sacramento histórico de liberación" (1977); "El pueblo crucificado. Ensayo de soteriología histórica" (1978); "Universidad, derechos humanos y 
mayorías populares" (1982); “Pobres" (1983); "Función liberadora de la filosofía" (1985); "El desafío de las mayorías pobres" (1989); "La construcción de un futuro distinto para la humanidad" (1988); "Utopía y profetismo en América Latina" (1989); "Historización de los derechos humanos desde los pueblos oprimidos y las mayorias populares" (1989); "EL mal común y los derechos humanos" (1989); "Utopía y profetismo desde América Latina. Un ensayo concreto de soteriología histórica" (1989) y "El pueblo crucificado. Un ensayo de soteriología histórica" (1989). Estos trabajos se encuentran compilados en los cuatro volúmenes sus Escritos teológicos (San Salvador: UCA Editores, 2000-2002).

5 Sobrino,Jon. "Monseñor Romero y la fe de Ignacio Ellacuría" en Sobrino,J.,Alvarado, R. Ignacio Ellacuria: «aquella libertad esclarecida» (San Salvador: UCA Editores, 1999), 14.

6 Gutiérrez, Gustavo. "No one takes my life from me, I give it freely" en Burke, K. Lasalle-Klein, R. (ed.) Love that produces hope: the thought of Ignacio Ellacuria (Minnesota: Liturgical Press, 2006), 69.

7 bid., 71.

8 lbid., 70.

9 "La idea de filosofía en Xavier Zubiri", 379-380.

10 Samour, Héctor. Voluntad de liberación: el pensamiento filosófico de Ignacio Ellacuría, 32-37; Alvarado Pisani,Jorge L.“Vida y pensamiento de Ignacio Ellacuría (1930-1989)",en Seminario Zubiri-Ellacuría. Voluntad de vida: ensayos filosóficos (Managua: UCA Managua, Managua, 1993), 138 y Valdés, Roberto. "La búsqueda filosófica inicial", en Ignacio Ellacuria: «aquella libertad esclarecida", 66-92.

11 “EL P. Aurelio Espinoza, SJ" en Escritos Filosóficos /1, 527.

12 lbid., 526.

13 "El despertar de la filosofía" en Escritos filosóficos / (San Salvador: UCA Editores, 1996), 48-50.

14 Los trabajos compilados son: "Marcelino, pan y vino" (1957), "El Doctor Zhivago como forma literaria" (1959), "Carta abierta al autor de Viridiana" (1962), en Escritos filosóficos I.

15 Veánse: “Ángel Martínez Baigorri, SJ." (redactado en 1954 y publicado en 1956), “Ángel Martínez, poeta esencial" (1958) y su correspondencia entre 1954-1956. Todos los textos en Escritos Filosóficos l.

16 “Ángel Martínez, poeta esencial”,157.

17 “Carta de Ellacuría a Ángel Martínez. Ecuador, julio de 1954", en Escritos filosóficos /, 202.

18 Estos trabajos aparecen, respectivamente en las ediciones de la Revista Cultura de El Salvador, números 11, septiembre-diciembre de 1956 (13-28) y 13, abril-junio de 1958 (148167). Ambos se encuentran compilados con el mismo título en "El despertar de la filosofía", 47-107.

19 “El despertar de la filosofía", 49.

20 lbid., 55.

21 "El objeto de la filosofia" (en ECA 396-397, San Salvador,1981, pp. 963-980). Para el presente trabajo nos atendremos a la paginación del artículo como aparece en la introducción y conclusiones de Filosofía de la realidad histórica (San Salvador: UCA Editores, 1990) editada por Antonio González: la primera parte del artículo es presentada como Introducción (15-46, que corresponden a las páginas 979 y parte de la página 980 de la edición original en $E C A$ ) y como Conclusiones (599-602, que corresponden a las 979-980 de ECA).

22 "Entrevista con Zubiri (Madrid)", en Escritos filosóficos II, 36. 
23 “Ortega, existencia desligada", en Escritos filosóficos 1, 265-270.

24 “Ortega y Gasset: hombre de nuestro ayer", en Escritos filosóficos 1,22.

25 “¿Quién es Ortega y Gasset?”, en Escritos filosóficos I, 40.

26 Además de esto, Ellacuría comenta:"Y hay que condenar esas argumentaciones superficiales que pretenden sustituir lo perenne y no meramente perfeccionarlo o completarlo -de suyo Ortega tiene teorías buenas sobre esto, pero su práctica es injusta frecuentemente-; hay que repudiar esa presentación falsificada del pensamiento tomista a la irrisión o repudio de quienes no lo conocen por sí mismos. Este es un error manifiesto y repetido de Ortega que lo comete con la escolástica y, más gravemente, con el cristianismo y su cultura en general [...] acerca de la actitud y doctrina orteguiana es que son enormemente peligrosas para quienes carezcan de una muy sólida formación cristiana y filosófica; su actitud, como desarrollé en otra ocasión, incita al naturalismo, al antropocentrismo, al egocentrismo, a la independencia moral más absoluta; su pensamiento, además de incitar a la destrucción de bases perennes y fundamentales, presenta sustitutivos filosóficos que a lectores superficiales pueden llevar, si no se escapa de su literalidad, a teorías materialistas, sensualistas, relativistas e idealistas, a teorías del conocimiento, éticas y teodiceas muy reprobables". En "Posibilidad y modo de aproximación entre filosofía escolástica y la filosofía vitalista moderna (Reflexiones ante el Libro de Ramírez: La filosofía de Ortega y Gasset)" en Escritos filosóficos 1, 226-227.

27 "Santo Tomás, hombre de su siglo" en Escritos filosóficos 1, 217.

28 "El tomismo, ¿es un humanismo?" en Escritos filosóficos /, 392.

29 "Entrevista con Zubiri (San Sebastián, 8 de septiembre de 1961)" en Escritos filosóficos II, 26.

30 "Entrevista con Zubiri (Madrid). Bilbao, 22 de marzo de 1963" en Escritos filosóficos II, 36.

31 Hay muchas más obras que comprenden la ingente producción filosófica de Xavier Zubiri, sin embargo, dado que muchos de estos trabajos han sido publicados tras la muerte del autor, hemos mencionado solamente las obras que se publicaron en vida de su autor. Mencionamos El hombre y Dios porque fue un texto en el cual Zubiri trabajó junto con Ellacuría, a quien Zubiri consideró como su más cercano colaborador y amigo. Véanse las cartas de $X$. Zubiri a I. Ellacuría de las fechas 27 de enero de 1963 (p. 54), 29 de enero de 1967 (pp. 58-59), 7 de septiembre de 1967 (pp. 60-61) y 16 de septiembre de 1968 (pp. 67-68), compiladas en los Escritos filosóficos II.

32 "Carta de I. Ellacuría a X. Zubiri (23 de febrero de 1963)" en Escritos filosóficos II, 56.

33 Véase Zubiri, X. "Sobre el problema de la filosofía” en Sobre el problema de la filosofía y otros escritos (1932-1944) (Madrid:Alianza Editorial-Fundación Xavier Zubiri),17-124.

34 "La idea de filosofía en Xavier Zubiri", 370.

35 Sobre la esencia, 32.

36 Ellacuría, Ignacio. "Conclusión: Carácter principial de la esencia" en La principialidad de la esencia en Zubiri, Tesis doctoral,1082, http://www.uca.edu.sv/centro-documentacion-virtual/ wp-content/uploads/2015/03/C07-1.c3.pdf

37 “Carta de I. Ellacuría a X.Zubiri (30 de abril de 1968)" en Escritos filosóficos I/, 62.

38 Ellacuría, Ignacio. Escritos teológicos / (San Salvador: UCA Editores, 2000), 39-105.

39 Este ingente trabajo tomará la forma de un curso en 1984 titulado "Filosofía de la historia", pero que constituyó la versión con la que contamos bajo el nombre de Filosofía de la realidad histórica, editada y publicada en 1990. 
40 Esto se puede evidenciar también en sus cursos "El sentido del hacer histórico", "Curso de metafísica" (ambos de 1974) y"El sujeto de la historia" (1978), a mbos compilados en los Cursos Universitarios (San Salvador: UCA Editores, 2009) y en el escrito inédito "Persona y comunidad en Zubiri" (1974). Además, según Héctor Samour (editor de los Cursos universitarios), parte del texto "El sentido del hacer histórico", recoge varias páginas del curso "Persona y comunidad", porque "el tema del sentido de la historia iba a ser uno de los capítulos centrales de Filosofía de la realidad histórica, por lo que este texto se puede considerar como un borrador de ese capítulo que Ellacuría ya no pudo terminar de redactar" (Nota introductoria de "El sentido del hacer histórico", p. 113).

41 Conferencia impartida en la Universidad Pontificia de Comillas, Madrid,1972. En Veinte años de historia en El Salvador (1969-1989). Escritos politicos vol. I (San Salvador: UCA Editores, 1991), 47-61.

42 "Filosofía y política", en Escritos politicos vol. I, 51.

43 lbid., 60-61.

44 No nos detendremos a realizar el análisis de cada una de estas componentes, puesto que sobrepasan los límites de esta exposición.

45 Divididos en 5 para la edición de 1990 de González. Los cuatro capítulos que originalmente Ellacuría había redactado tienen en el orden que sigue: a) la materialidad de la historia; b) la componente social y la componente personal de la historia; c) la estructura temporal de la historia; y d) la realidad formal de la historia.

46 Véanse: Cursos Universitarios. Los cursos aparecen en el siguiente orden: "El sentido del hacer histórico" (113-141), "Curso de metafísica" (143-252), "El sujeto de la historia” (281326) e incluimos "Ideología e inteligencia" (327-378), porque es una cuestión que atañe al problema ideológico analizado desde el carácter situado y abierto de la inteligencia, tema capital que Ellacuría retoma de la filosofía zubiriana.

47 Los escritos políticos de Ignacio Ellacuría se encuentran compilados en cuatro volúmenes, con el título Veinte años de historia en El Salvador (1969-1989). Escritos politicos (San Salvador: UCA Editores, 1991).

48 "Filosofía, ¿para qué?" en Escritos filosóficos vol. III (San Salvador: UCA Editores, 2001), 116-119.

49 lbid., 122.

50 lbid., 123.

51 lbid., 127.

52 Filosofía de la realidad histórica, 43-44.

53 lbid., 46.

54 "Función liberadora de la filosofía", 94.

55 lbid., 98.

56 lbid., 98-99.

57 lbid., 112.

58 En Escritos teológicos vol. // (San Salvador: UCA Editores, 2000), 233-293.

59 "Quinto centenario de América Latina, ¿descubrimiento o encubrimiento?" en Escritos teológicos /I, 533-534. “Utopía y profetismo", 249. 
60 "Utopía y profetismo", 258-260.

61 "Historicidad de la salvación cristiana", en Escritos teológicos 1, 571-596.

62 "Utopía y profetismo", 250

63 Filosofía de la realidad histórica, 467-468.

64 “El desafío de las mayorías pobres", en Escritos teológicos l, 359. 